\title{
Language Influences Thought? Or the Reverse?
}

\author{
Feng Li* \\ English Department \\ School of Foreign Language, \\ Jinling Institute of Technology \\ Nanjing, China, 211169 \\ Lifeng_7820@163.com
}

\begin{abstract}
The Whorfian Hypothesis has been a source of controversy since it was first articulated both in its strong form 'language determines thought' and its weaker form 'language influences thought', and it has influenced disciplines beyond linguistics. This article intends to regard the relationship between language and thought from a different perspective: namely, how thought may determine language. It analyzes how thought determines language lexically, semantically and structurally.
\end{abstract}

Keywords-Whorfian Hypothesis; perception and thought; lexicon; expression; structure

\section{INTRODUCTION}

In the well-known classical Chinese novel Dream of Red Chamber, the hero Zhen Baoyu was very naughty and reluctant to study. And so, he was more often than not punished by his father. When severely being beaten, he would call out aloud "elder sisters, younger sisters". After that, his maids teased him by asking "Why did you call out "elder sisters and younger sisters"? You wanted us to rescue you?" Baoyu responded in a very serious manner, "When I call out 'elder sisters younger sisters', my pain relieves."

This naughty boy did not expect that his crazy idea would have found favor with Benjamin Lee Whorf if they had known each other. After studying Native American languages, Whorf attempted to account for the ways in which language affected perception or thought, later identified as the Whorfian hypothesis. In his posthumous book, he maintained that "language is not merely a reproducing instrument for voicing ideas but rather is itself the shaper of ideas, the program and guide for the individual's mental activity"[7]. In the past, many writers of science fiction and utopias often seized upon the Whorfian hypothesis as a tool for creating new societies. They generally began with a simplified version of the strong form of the hypothesis going something like "Language determines perception and therefore thought". For example, George Orwell invented a fictional language --- Newspeak in his novel Nineteen Eighty-Four. Newspeak was a controlled language created by the totalitarian state Oceania as a tool to limit freedom of thought and concepts that pose a threat to the regime, such as freedom, self-expression, individuality and peace.

This hypothesis, having influenced disciplines beyond linguistics, including philosophy, neurobiology, anthropology, psychology and sociology, has been controversial since first outlined. Consequently, it is amusing to see that recent positions range from those holding that specific words or language structures cause "radical restructuring of cognition" [5] to those that maintain that there is a "remarkable independence of language and thought"[3], even when based on much the same kinds of findings.

\section{EMPIRICAL RESEARCH ON LANGUAGE AND THOUGHT}

Much empirical research has been conducted in domains such as color terminology, space, time, number, etc. Some researchers conclude through experiments that the spatial terminology used by the subjects in their native tongue predict the way they solve such problems as reordering objects according to their memory; in other words, speakers of languages which use different spatial systems solve non-verbal spatial tasks in distinct ways[4][6]. Their view sounds reasonable, but they did not explore why these languages use different terminologies for spatial system, which is just what this article is interested in doing.

Some researchers like to research by combining temporal terms with spatial terms, such as Boroditsky[1]. She argues that there are spatial morphemes like "up" and "down" as well as "front" and "back" in Mandarin to talk about time, therefore, native Mandarin speakers think about time both vertically and horizontally, even when they are thinking in English; while in English there are only horizontally spatial morphemes such as "forward" or "backward" to talk about time, English speakers tend to think about time only in horizontal way.

Superficially, she is right. But why are there both horizontal and vertical spatial morphemes in Mandarin to talk about time? This may be attributed to the fact that Chinese people think about time in both spatial ways. We think that our fathers and forefathers should be on top of us out of respect, and naturally, our descendants should be under us. So, it is not difficult for us to regard the past as "up" and the future as "down". In English there are no such vertically spatial morphemes to talk about time just because English speakers have no such understanding or thinking about time. On the other hand, both languages own horizontally spatial morphemes to talk about time, which means they share some understanding about time, so they created similar expressions to talk about time in this case. Logically, Mandarin speakers have both vertical and horizontal understanding about time; this understanding or thinking about time determines that they chose both vertically and horizontally spatial morphemes to talk about time; then later, when people 
acquire or learn this language, they surely pick up its unique way of thinking about time.

In fact, Boroditsky only discussed spatial morphemes about time. We can also look into other expressions of 'time', In Mandarin, 'time' is “时光” or “光阴” , which means 'light and dark'. This expression reflects how Chinese people perceive 'time'. Two more examples are listed as below.

\section{1) 时光飞逝}

Time flies and is gone.

\section{2) 光阴 似 箭}

\section{Time is like arrows.}

As to the two Mandarin idioms about 'time', English speakers can understand them quite well, which means that both have much in common about understanding the quality of 'time'. But Mandarin speakers also think time is gone ultimately and never comes back; so, they like to create expressions of "being gone" to describe "time' besides "being quick and fast".

This article agrees, mostly, with what these researchers have discovered in their research, i.e. different languages may shape people's cognition, such as in the cases of spatial terms and temporal terms. But this article's interest lies in what lead to the similar and different linguistic forms and contents across languages. It will regard the relationship between language and thought from another perspective; or in other word, this article intends to put forward a new hypothesis --- thought determines language. Language can be said to be the product of thought as well as one of the important conveyors of thought.

\section{THOUGHTS DETERMINE LANGUAGE}

\section{A. Lexicon}

People in the world saw the sun, the moon and the stars appear and disappear, watched animals and plants grow and die and experienced birth and death. They created language to describe all these phenomena --- what is perceived and thought of in the world. The similarities in people's perception and cognition of the world make it possible for human languages to possess lexicons signifying the same physical objects, natural phenomena and human emotions, which lays the foundation for translatability across all human languages. Despite the differences in sounds and forms, Chinese and English have much in common in the lexicons with identical meanings. For instance:

rì

\section{日 sun}

yùe

\section{月 moon}

However, if we take a closer look, it will be obvious that some lexical items cannot be literally translated between the two languages, i.e. some lexical items in one language have no exact equivalents in the other. The reason lies in there being certain differences between the physical environments where
Chinese and English speakers live, which results in their various perception and cognitions of the world. The staple food of Chinese people is rice, so they created the phrase of 饭碗 (rice bowl) to refer to one's job and 鱼米之乡 (a land full of fish an rice) to describe a land abounding with foods. However, suppose you asked a native English speaker whether he could help find a 'rice bowl' for you, he would be definitely confused if without further explanation. To be sure, when you introduce your hometown is a 'land full of fish and rice', most likely, the foreign listener will not imagine a similar picture to yours, because they have perceptions and understandings of THEIR living surroundings different from your own, which determines that they surely created lexical items unique to their world. In the similar situations, English speakers may prefer to say 'I earn my bread in that factory', and 'my hometown is a land of milk and honey'. Naturally, these expressions sound strange to Chinese speakers. Actually, in this case, Whorf's 'Eskimo snow terms' can be taken as a good example to prove that how people perceive their environment will determine or influence their lexicons.

What people perceive and think of the world can also be traceable to the cultural and social level, not only limiting to natural world. "A culture is made up of people who have a reality consensus, itself made up of statements .... which they all agree to believe" [2]. There are some parts, if not all, in that Chinese people perceive the world in a differently cultural perspective from English speakers, which can account for the differences in the lexicons between the two languages. Chinese people don't worship a unified religion, but truly they feel awe to the mighty Nature or Heaven. They think everything in the world, day and night, sun and rain, growing and withering, is controlled by a mysterious power from above, and thus naming it '天', ‘老天', or '老天爷'. If literally translated, it should be 'the sky' or 'Lord in the sky'. When in danger or despair, Chinese people pray to HIM for help; when in shock or excitement, Chinese people exclaim HIM. Apparently, this perception and understanding of 'the sky' of Chinese people cannot be traced in native English speakers, who generally employ a religious term GOD in similar situations.

In Chinese culture, people attach great importance to family bonds and prefer a big family with three or more generations living together. (Today, some changes have taken place, and more and more nuclear families emerge.) Consequently, Chinese people use specific terms to signify a specific family member. By contrast, English tends to apply a general term to a group of people.

Chinese people create specific kinship terms to reveal the clear link between two family members or relatives, while native English speakers are inclined to employ a general term even though they have the same relative relationship as Chinese people in life. An abundance of kinship terms in Chinese originates from the Chinese peoples' great emphasis on big families and on kinship. And interestingly, if examining the above terms more carefully, we may find there is one term for a father's elder brother and one term for father's younger brother respectively, while there is only one single term to signify mother's sisters, mother's brothers or father's sisters, regardless of whether they are elder or younger. Such lexicons 
reflect the fact that Chinese culture used to be male-centered. Therefore, the culture or value of one community reveals how and what the community perceived and thought of the world spiritually, and such perceptions and cognitions determine or affect how the community creates the lexicons of their language, more or less, elegant or harsh. Nowadays, more and more nuclear families have emerged in China and family bonds are less and less stressed in Chinese people's life. Accordingly, a tendency of using general kinship terms instead of specific terms, very much like English speakers, has arisen in Chinese culture, for example, '姐姐' (elder sister) now can signify all the elder girls from one's own parents or one's uncle or one's aunt. This phenomenon as well illustrates that thought determines language.

\section{B. Similar expressions with different implication}

Generally, there has been much in common across the various physical environments where people speaking different languages settle in. They see similar natural phenomena, such as stars in the sky, colors in the nature, and changes of weather; they also experience similar socializing activities, such as greeting, complimenting, and learning. People created languages to describe these similar natural phenomena and socializing activities. However, due to a different perception and understanding of the world, a language even signifying the same natural phenomenon may carry different connotations, or even in the same social context, different forms and contents are employed to socialize in different languages.

Most human languages possess the terms of colors, some more in the number some less. '红色'(red) is a popular color in Chinese culture, because it is not only used to refer to a color in nature, but also given one connotation of prosperity, jubilation and fortune by Chinese people.

Greetings seem of no importance at all, for it does not require a response of substantial content. But actually it is one of the most socializing activities, which may affect how you deal with the people around you and whether you can get along well with them. Chinese people like to greet with:

--- 吃过饭了? Have you had your meal?

--- 吃了。你呢? Yes. How about you?

It would be weird to greet another with this sort of language for two native English speakers, who do not think of eating essential to life as do the Chinese people, which determines that a native English speaker could not create such linguistic expressions as the Chinese people to greet others. Undoubtedly, the rich vocabulary about foods in Chinese language originates from Chinese people's great emphasis and liking of foods.

Complimenting is common in human social communication. But how to respond to compliments varies greatly when people manifest different thinking styles. Chinese people consider it a virtue to be modest and even to underestimate oneself. When receiving any compliment, they will behave in a modest and shy manner and try to deny the compliment, which is reflected in Chinese language like:

--- 你儿子可真出色！Your son is so excellent!
--- 没有, 没有, 还要努力。 No, no. He needs more working.

Not like Chinese people, native English speakers will accept compliments happily with a simple expression 'Thank you'. So, it is understandable that native speakers regard Chinese people as not confident or even hypocritical when they first meet. Actually, the reason why Chinese people chose a different expression to respond to compliments is determined by what they perceive or think of this issue, or in this case we can say, by part of their culture.

\section{Structure}

To prove that thought determines language in structure is a most complicated and difficult project. In lexicons and meanings of one language we can easily discover the reflection of thought. But the issue of structure is much more abstract and intractable to explore. Merely asking how the thought of one group of people determines their language structure is surely hard to answer. However, by contrasting two languages in structure, significant differences between them may provide some insight to justify this hypothesis.

Analyses above reveal that Western thought is characterized by rule or law orientated, detailed, analytical and logical while Chinese thinking style is featured with context or situation specific, holistic, intuitive, compatible. We may not conclude what exactly Chinese language structure is supposed to be, but Chinese thinking style tells us that its structure probably gives less emphasis on grammatical forms, but more on language contexts and on wholeness of objects and events. Western thinking style determines the structure of English can be analytical and logical, which requires it to possess some grammatical forms so that messages can be understood correctly even isolated from contexts. Some illustrations are displayed below.

马吃草。

Horse eat grass

鸟自由地飞。

Bird freely fly

The two examples reveal that unlike English, 1) Chinese has no need for capital initial letters since a Chinese character is a single whole indivisible structure; 2) the nouns in the sentences appear in their original forms, regardless of singular form or plural form; 3) the predicate verbs do not have grammatical change such as tense, aspect, or third person singular.

Have a look at the following two English sentences.

\section{A horse eats grass.}

Horses eat grass.

Both sentences are acceptable in English for showing the same general meaning, as long as the grammatical forms are conformed. But such a Chinese sentence as 一马吃草(A horse eat grass) will definitely be understood as there is ONE SINGLE horse eating grass rather than as a general meaning. Therefore, the nouns in Chinese sentences usually refer to them 
as a whole rather than as individual unless a numeral is added to them. Apart from that, in most cases we have to depend on contexts to understand when a story happens and whether it is real or just imagined, for there are no grammatical changes to predicate verbs in Chinese.

Obviously, the understanding of the Chinese sentences is greatly context dependent. To understand a Chinese sentence, you have to closely link it to the previous one. However, English sentences seem more context-isolated. Saying 'yes', the speaker always means he has had breakfast, while saying 'no', he consistently means he has not.

\section{CONCLUSIONS}

The Whorfian Hypothesis has been defended and challenged in its strong version 'language determines thought' and its weak version 'language influences thought' since it was first proposed. This article puts forward a fresh perspective on the relationship between language and thought--thought may determine language in its lexicon, meaning and structure. How people think about the world determines how they speak; in turn, one's language influences one's thinking, for when you accept a language, you accept the thoughts and thinking ways it reflects more or less, willingly or unwillingly. This article explores how thinking determines and thereby produces language, while other researchers have studied how one's language shapes his thinking since the language has been here.

People live in different natural environments, which contribute to how they perceive and think of the world differently more or less. The similarities in perception and thought of the world lead to two languages' literal translatability and easy comprehensibility, while the differences in perception and thought about the world result in abundance or scarcity of terms in a certain aspect, various linguistic expressions with diversified implications in the same situations, and structural variations in morphology and syntax. Admittedly, language does influence thought but only in the sense that some languages are capable of expressing some phenomena with more ease or some characteristics of one language are capable of facilitating human cognitions better in a certain aspect. Just because thought determines language, learning a foreign language usually provides one access to its speakers' thought, which makes it possible to accept their thought or to be assimilated by their thought. So, it is understandable that many language reforms and language invasions have taken place in the world, such as the Emperor Qin (the first emperor of China) spared no effort to promote a unified Chinese language throughout his empire; Alexander the Great brought Greek language wherever he conquered; After Franco-Prussian War in 1871, Germany ordered that all students on the ceded land from France should learn German instead of French; Japan forced Manchu people and Taiwan people to learn Japanese during its colonization till the year of 1945. Nowadays, along with the globalization in all aspects, people are getting familiar and identified with thoughts from other peoples and other cultures so much that sometimes they neglect linguistic differences derived from differences in thought.

\section{REFERENCES}

[1] Boroditsky, L. "Does language shape thought?: Mandarin and English speakers' conceptions of time", Cognitive Psychology 43, pp.1-22, 2001

[2] Elgin, S. H. More about the gentle art of verbal self-defense, Englewood Cliffs: Prentice-Hall, 1983.

[3] Heider, E. \& Oliver, D. C. "The structure of color space in naming and memory for two languages", Cognitive Psychology 3, pp. 337-354, 1972.

[4] Levinson, S. C. Spatial language, in L. Nadel (Ed.), Encyclopedia of cognitive science (pp. 131-137). London: Nature Publishing Group, 2003.

[5] Majid, A., Bowerman, M., Kita, S., Haun, D. B., \& Levinson, S. C. "Can language restructure cognition? The case for space", Trends in Cognitive Science, 8 (3), pp. 108-114, 2004.

[6] Pederson, E., Danziger, E., Wilkins, D., Levinson, S. C., Kita, S., \& Senft, G. "Semantic typology and spatial conceptualization", Language, 74 (3), pp. 557-589, 1998.

[7] Whorf, B. L. Language, thought and reality, (J. Carroll, Ed.). Cambridge, MA: MIT Press, 1956. 